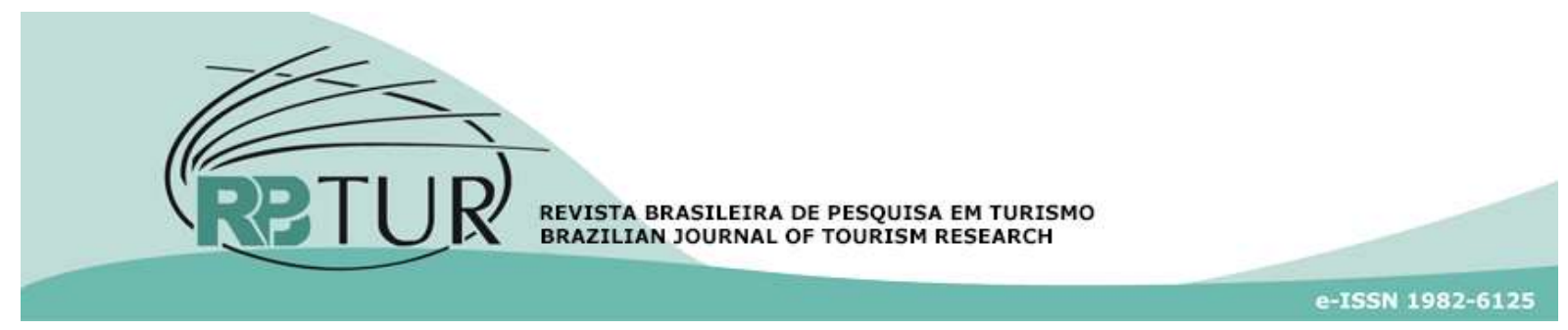

Artigo

DOI: http://dx.doi.org/10.7784/rbtur.v12i2.1392

\title{
A geografia econômica relacional e sua aplicação nos estudos de arranjos produtivos do turismo
}

\section{The relational economic geography and its use in tourism clusters studies}

\section{La geografía económica relacional y su aplicación en los estudios de aglomerados productivos del turismo}

\author{
Adriana Fumi Chim-Miki ${ }^{1}$ \\ Thays Cristina Domareski Ruiz ${ }^{2}$
}

Resumo: Este artigo apresenta a evolução da teoria da Geografia Econômica Relacional (GER) como uma base teórica de análise regional e de destinos turísticos. São apresentadas as origens, fundamentos, tendências de conceituação e críticas da GER. Também é realizada uma contextualização mediante uma comparação entre as análises de destinos turísticos baseadas em aglomerados produtivos (redes, distritos, clusters e arranjos produtivos locais) e a análise da perspectiva da GER. É um estudo qualitativo, de revisão teórica e conceitual, que tem por objetivo verificar se a GER é uma perspectiva complementar aos clássicos estudos de aglomerações produtivas ou se é uma perspectiva que pode substituí-las, suprindo algumas deficiências que têm sido apontadas pelos pesquisadores. Conclui-se que a GER pode ser utilizada para estudos de destinos turísticos, independentemente da forma de organização territorial/produtiva que este tenha. Assim como poderá gerar ferramentas para traduzir o pensamento relacional, tirando-o da abstração e trazendo esta concepção teórica para a prática de gestão territorial de destinos turísticos.

Palavras-chave: Geografia Econômica Relacional. Destinos Turísticos. Aglomerados Produtivos. Pensamento relacional.

\footnotetext{
${ }^{1}$ Universidade Federal de Campina Grande (UFCG), Paraíba. Pesquisa Bibliográfica para Desenvolvimento da base teórica do artigo; Desenvolvimento da Metodologia; Análise e discussão da proposta do artigo; Elaboração da figura e quadros comparativos.

2 Universidade Federal do Paraná (UFPR), Curitiba, PR. Pesquisa Bibliográfica para Desenvolvimento da base teórica do artigo; Revisão da literatura; Análise e discussão da proposta do artigo; Revisão Final.
} 
Abstract: This paper presents the evolution of the theory of Relational Economic Geography (REG) as a theoretical basis to regional analysis and to tourism destinations analysis. It presents the origin, foundations, conceptualization trends and criticism of this perspective. It also describes a contextualisation through a comparison between the analyzes of tourist destinations based on productive clusters (networks, districts, clusters and local productive arrangements) and analysis from the GER perspective. It is a qualitative study, of theoretical and conceptual revision, whose objective is to verify if the GER is a complementary perspective to the classic studies of productive agglomerations or if it is a perspective that can substitute them, supplying some deficiencies that have been pointed out by the researchers. It concluded that the REG can be used to tourism destination studies, regardless of the territorial organization or productive that it has. As well as, REG perspective can generate tools to translate the relational thinking, taking it out of abstraction and bringing this theoretical concept to the practice of territorial management of tourism destination.

Keywords: Relational Economic Geography. Tourism Destination. Agglomeration Productive Systems. Relational thinking.

Resumen: Este artículo muestra la evolución de la teoria de la Geografía Económica Relacional (GER) como una base teórica de análisis regional y de destinos turísticos. Se presenta los orígenes, fundamentos, tendencias de conceptualización y críticas de esta perspectiva. También una contextualización es presentada a través de una comparación entre los análisis de destinos turísticos basadas en aglomerados productivos (redes, distritos, clústeres) y el análisis por la perspectiva da GER. Es un estudio cualitativo, con revisión teórica y conceptual, que objetiva verificar si la GER es una perspectiva complementar a los clásicos estudios de aglomeraciones productivas o si es una perspectiva que puede sustituirlos, mejorando algunas debilidades que han sido apuntadas por los investigadores. Se concluí que la GER puede ser utilizada para estudios de destinos turísticos, independientemente de la forma de organización territorial/productiva que éste tenga. Así como, podrá generar herramientas para traducir el pensamiento relacional, sacándolo de la abstracción y poniendo esta concepción teórica para la práctica de la gestión territorial de los destinos turísticos.

Palabras clave: Geografía Económica Relacional. Destinos Turísticos. Aglomerados productivos. Pensamiento relacional.

\section{INTRODUÇÃO}

Desde o trabalho inicial de Amin e Thrift (2000) que sugeriu outra direção para a Geografia Econômica trazendo conceitos de outras ciências sociais, tem ocorrido um distanciamento das ideias da economia neoclássica (Bathelt \& Glückler, 2003). Tem sido grande o uso da perspectiva econômica evolutiva e relacional nos estudos, abrindo discussões promissoras para o desenvolvimento de novas teorias (Boschma \& Frenken, 2010). Comprovando que o tema tem atraído atenção dos pesquisadores, em abril de 2009, o Times Higher Education apresentou uma análise de dados da Thomson Reuters, Essential
Science Indicators (ESI), evidenciando a "Geografia Econômica Relacional e Evolutiva" como o terceiro tópico mais pesquisado em ciências sociais - com 2.232 citações em 41 artigos científicos (Randelli, Romei \& Tortora, 2014; Domareski-Ruiz; Chim-Miki \& Gândara, 2014).

As abordagens relacionais têm sido mais frequentes nos estudos contemporâneos e defendidas por muitas lideranças acadêmicas (Sunley, 2008). No entanto, sérias críticas e dúvidas ainda circundam esta abordagem, que se presume como um novo pensamento, um paradigma, buscando fundamentar-se em uma teoria. Alguns autores salientam que uma "onda de entusiasmo" to- 
mou conta dos debates teóricos, ocorrendo o perigo de comprometer o debate crítico e a avaliação (Storper, 1997; Boggs \& Rantisi, 2003; Overman, 2004; Yeung, 2005; Sunley, 2008).

O enfoque relacional como abordagem é um conjunto disperso de teorias e ideias que compartilham características comuns, mas diferem em aspectos importantes (Bathelt, 2006). Estas abordagens têm sido usadas para analisar modos de coordenação econômica ou de governança onde existam relações colaborativas e de confiança, que favoreçam a troca de conhecimentos (Jones \& Hesterly; Borgatti, 1997; Dyer \& Singh, 1998; Rutten, 2004 Capello \& Faggian, 2005).

Segundo alguns pesquisadores, o nível de pesquisas existentes na área da Geografia Econômica Relacional - GER (Relational Economic Geography - REG) ainda não tem suficiente base conceitual e metodológica para dar um sentido prático e gerar condições de aplicabilidade no contexto real, especialmente fundamentar pesquisas empíricas, porém, a perspectiva parece adequada a muitas análises direcionadas a redes organizacionais, tendo potencial para contribuir com pesquisas científicas e análises empíricas (Bathelt \& Glückler, 2003; Boschma \& Frenken, 2006; Boschma \& Martin, 2007; Sanz-Ibáñez \& Antón Clavé, 2014).

Primeiramente, este artigo apresenta e discute o pensamento relacional, trazendo ao debate acadêmico a proposta da GER, sua origem e fundamentação, incentivando a comunidade científica a unir-se ao esforço de consolidar uma base teórica que viabilize o uso deste enfoque em diversas áreas. Contextualiza-se na atividade turística, e tem como objetivo principal discutir se o uso da GER complementa ou substitui a tradicional análise de destinos turísticos que o considera como rede, distrito, cluster ou APL (arranjos produtivos locais).

A escolha da atividade turística para esta discussão foi porque é uma atividade econômica com muitas peculiaridades baseadas na interdependência dos atores para constituir o destino como produto integral (Della Corte \& Sciarelli, 2012). Por estes objetivos, classifica-se como uma pesquisa qualitativa de estrutura teórica/conceitual onde se consideram as seguintes questões: Como a GER pode contribuir na análise de destinos turísticos? A GER substitui a perspectiva de redes, distritos, clusters e arranjos ou ela complementa? A GER pode ser aplicada em qualquer um destes arranjos produtivos ou existem limitações? Assim, essa pesquisa se caracteriza como analítica e descritiva, de abordagem qualitativa com base em uma revisão teórica e conceitual a partir da consulta a artigos publicados nas bases de dados Scopus, Web of Science, Science Direct e Scielo que estavam relacionados a GER, bem como, o seguimento de obras mais citadas pelos autores consultados, proporcionando uma visão ampla e histórica da GER enquanto perspectiva conceitual.

\section{O PENSAMENTO RELACIONAL COMO BASE DA GEOGRAFIA ECONÔMICA RE- LACIONAL (GER): ORIGENS E CONCEI- TOS}

Desde os anos 1990 os geógrafos econômicos realizam estudos sobre a complexidade das relações entre atores e estru- 
turas e como estas afetam a dinâmica espacial das atividades econômicas consolidando a chamada Geografia Econômica Relacional (Amin, 1998; Dicken \& Malmberg, 2001; Ettlinger, 2001; Bathelt \& Gluckler, 2003; Boggs \& Rantisi, 2003). Pesquisas com diferentes contribuições e fundamentações surgiram dentro da Geografia Econômica, entre as quais cabe destacar: a construção relacional de identidade espacial (Amin \& Thrift, 2000) e as obras relacionadas às chamadas "janelas de oportunidade locacional" e as "interpendências não comerciais" (Scott, 1988; Storper \& Walker, 1989). Juntam-se a esta discussão as contribuições da sociologia econômica com as noções de enraizamento social e relações baseadas em confiança (Granovetter, 1985) e mais recentemente, tem se discutido a produção social do conhecimento (Faulconbridge, 2006).

O Quadro 1, derivado de um trabalho em que Yeung (2005) propôs 'repensar' a GER, ele sintetiza uma série de estruturas relacionais que se analisam por conceitos geográficos, econômicos e de gestão, refletindo em uma diversa tipificação de manifestações espaciais que conduzem a conceitos que atualmente são utilizados nas análises de desenvolvimento e competitividade regional.
Sunley (2008) indica que as origens do pensamento relacional na Geografia Econômica se estruturaram na sociologia com base no enraizamento das redes na vida econômica, e salienta que a popularidade deste pensamento tem crescido em função da visão de que o capitalismo contemporâneo é cada vez mais relacional. As mudanças geradas pelo capitalismo tardio são caracterizadas pela reestruturação e globalização dos processos produtivos, gerando novas formas de coordenação entre empresas (SanzIbáñez \& Antón Clavé, 2014). Dicken, Kelly, Olds e Yeung (2001) consideram que a perspectiva relacional é um ponto de partida para o trabalho empírico, assim, a GER se destaca como uma das ferramentas para analisar as regiões e como seus ativos relacionais podem gerar vantagens para seu desenvolvimento (Coe et al., 2004).

O pensamento relacional, que se firmou a partir das abordagens e estudos teórico-empíricos, pode ser agrupado em quatro grandes escolas do pensamento relacional. 0 surgimento destas escolas reuniu os acadêmicos que partiram da Geografia Econômica e Regional para ingressar com estudos com cunho relacional, dos quais alguns estão citados no Quadro 2. 
Quadro 1 - Estruturas Relacionais na Geografia Econômica e seus antecedentes

\begin{tabular}{|c|c|c|c|c|}
\hline $\begin{array}{c}\text { Estruturas Rela- } \\
\text { cionais }\end{array}$ & Conceitos Temáticos & $\begin{array}{c}\text { Autores Princi- } \\
\text { pais }\end{array}$ & $\begin{array}{c}\text { Manifestação Espa- } \\
\text { cial }\end{array}$ & Antecedentes \\
\hline \multirow{5}{*}{$\begin{array}{l}\text { Ativos relacio- } \\
\text { nais } \\
\text { no desenvolvi- } \\
\text { mento local e re- } \\
\text { gional }\end{array}$} & $\begin{array}{l}\text { Espessura instituci- } \\
\text { onal }\end{array}$ & \multirow{5}{*}{$\begin{array}{l}\text { Ash Amin; } \\
\text { Phil Cooke; } \\
\text { Anders Malm- } \\
\text { berg; } \\
\text { Ron Martin; } \\
\text { Peter Maskell; } \\
\text { Kevin Morgan; } \\
\text { Allen Scott; } \\
\text { Michael } \\
\text { Storper; } \\
\text { Nigel Thrift. }\end{array}$} & $\begin{array}{l}\text { Novos espaços } \\
\text { Industriais }\end{array}$ & $\begin{array}{c}\text { Economia Evolutiva e } \\
\text { Institucional }\end{array}$ \\
\hline & $\begin{array}{l}\text { Interdependências } \\
\text { comerciais e não co- } \\
\text { merciais }\end{array}$ & & Distritos Industriais & $\begin{array}{l}\text { Nova sociologia } \\
\text { econômica }\end{array}$ \\
\hline & $\begin{array}{l}\text { Tendências de aglom- } \\
\text { eração }\end{array}$ & & Clusters & $\begin{array}{c}\text { Análise organi- } \\
\text { zacional }\end{array}$ \\
\hline & $\begin{array}{l}\text { Atmosfera e meio so- } \\
\text { cial }\end{array}$ & & $\begin{array}{c}\text { Regiões de aprendi- } \\
\text { zagem }\end{array}$ & Estudos urbanos \\
\hline & Capital social & & $\begin{array}{l}\text { Nós Marshallianos } \\
\text { em cidades globais }\end{array}$ & $\begin{array}{l}\text { Estudos políticos da } \\
\text { democracia e dos } \\
\text { movimentos sociais }\end{array}$ \\
\hline \multirow{4}{*}{$\begin{array}{l}\text { Enraizamento re- } \\
\text { lacional nas re- } \\
\text { des: atores soci- } \\
\text { ais, empresas e } \\
\text { organizações }\end{array}$} & $\begin{array}{c}\text { Redes Inter organi- } \\
\text { zacionais } \\
\end{array}$ & \multirow{4}{*}{$\begin{array}{l}\text { Ash Amin; } \\
\text { Peter Dicken; } \\
\text { Meric Gertler; } \\
\text { J.K.Gibson-Gra- } \\
\text { ham; } \\
\text { Gernot Grabher; } \\
\text { Roger Lee; } \\
\text { Linda McDowell; } \\
\text { Jonathan Mur- } \\
\text { doch; } \\
\text { Nigel Thrift; } \\
\text { Sara Whatmore; }\end{array}$} & $\begin{array}{c}\text { Tensões Global-lo- } \\
\text { cal }\end{array}$ & $\begin{array}{c}\text { Nova sociologia } \\
\text { econômica }\end{array}$ \\
\hline & Redes de atores & & $\begin{array}{l}\text { Produção diferenci- } \\
\text { ada da organização } \\
\text { dos espaços de pro- } \\
\text { dução }\end{array}$ & $\begin{array}{c}\text { Análise organizacio- } \\
\text { nal e estudos de ges- } \\
\text { tão }\end{array}$ \\
\hline & $\begin{array}{c}\text { (Global) cadeias de } \\
\text { produção }\end{array}$ & & $\begin{array}{c}\text { Dependência da } \\
\text { Trajetória }\end{array}$ & $\begin{array}{l}\text { Pós-estruturalismo e } \\
\text { estudos feministas }\end{array}$ \\
\hline & $\begin{array}{l}\text { Relações híbridas e } \\
\text { de gênero }\end{array}$ & & $\begin{array}{l}\text { Geografias híbridas } \\
\text { e trajetórias múlti- } \\
\text { plas }\end{array}$ & $\begin{array}{l}\text { Ciência e estudos } \\
\text { tecnológicos }\end{array}$ \\
\hline \multirow{4}{*}{$\begin{array}{l}\text { Escalas Relacion- } \\
\text { ais }\end{array}$} & $\begin{array}{c}\text { Escala geográfica } \\
\text { como construto rela- } \\
\text { cional }\end{array}$ & \multirow{4}{*}{$\begin{array}{l}\text { Neil Brenner; } \\
\text { Kevin Cox; } \\
\text { Bob Jessop; } \\
\text { Jamie Peck; } \\
\text { Neil Smith; } \\
\text { Erik } \\
\text { Swyngedouw; } \\
\text { Peter Taylor }\end{array}$} & $\begin{array}{c}\text { Escalonamento Ge- } \\
\text { ográfico }\end{array}$ & Geografia \\
\hline & $\begin{array}{c}\text { Relações sociais } \\
\text { como construto esca- } \\
\text { lar }\end{array}$ & & $\begin{array}{l}\text { Políticas de Globali- } \\
\text { zação }\end{array}$ & Sociologia \\
\hline & \multirow{2}{*}{$\begin{array}{l}\text { Redimensionamento } \\
\text { e Reterritorialização }\end{array}$} & & $\begin{array}{c}\text { Governança Urbana } \\
\text { e Regional }\end{array}$ & \multirow[b]{2}{*}{ Análise Institucional } \\
\hline & & & $\begin{array}{c}\text { Regulação social } \\
\text { dos mercados de } \\
\text { trabalho locais }\end{array}$ & \\
\hline
\end{tabular}

Fonte: Yeung (2005) 
Quadro 2 - Escolas do Pensamento Relacional

\begin{tabular}{|c|c|c|}
\hline Escola & Pensamento Relacional & Autores \\
\hline $\begin{array}{l}\text { Escola do Reino } \\
\text { Unido de Geo- } \\
\text { grafia Evolutiva }\end{array}$ & $\begin{array}{l}\text { Contingência em ação econômica e realismo } \\
\text { crítico; Realidades sociais de ação econômica; } \\
\text { Concepções ator-rede sofisticados; Visão da } \\
\text { desterritorialização do conhecimento/criação; } \\
\text { Construção relacional da identidade espacial. }\end{array}$ & $\begin{array}{l}\text { Massey (1985); Sayer (1992; 2000); } \\
\text { Clark (1983); Amin (1994); Thrift } \\
\text { (2000a); Lee (2002); Thrift (2000b); } \\
\text { Amin \& Thrift (2003); Allen (2003); } \\
\text { Massey (2004); Amin \& Cohendet } \\
\text { (2004); Clark \& Tracey (2004). }\end{array}$ \\
\hline $\begin{array}{l}\text { Escola Californi- } \\
\text { ana de Geografia } \\
\text { Econômica }\end{array}$ & $\begin{array}{l}\text { Forças de criação de espaço dos agentes } \\
\text { econômicos; Janelas de oportunidade locacio- } \\
\text { nal; Conceito de interdependências não nego- } \\
\text { ciadas; Conceito de "Holy Trinity" (Santíssima } \\
\text { Trindade: Tecnologia, organização e territó- } \\
\text { rio); }\end{array}$ & $\begin{array}{l}\text { Walker \& Storper (1981); Scott } \\
\text { (1988); Storper \& Walker (1989); } \\
\text { Storper (1997); Storper e Venables } \\
\text { (2004). }\end{array}$ \\
\hline $\begin{array}{l}\text { Escola de Man- } \\
\text { chester de Redes } \\
\text { de Produção Glo- } \\
\text { bal }\end{array}$ & $\begin{array}{l}\text { Concepção de rede de ação econômica; Co- } \\
\text { nectividade global; Aspectos sócios institucio- } \\
\text { nais e imersão cultural na interação econô- } \\
\text { mica internacional. }\end{array}$ & $\begin{array}{l}\text { Yeung (1998); Dicken et al. (2001); } \\
\text { Dicken \& Malmberg (2001); Hender- } \\
\text { son et al. (2002); Coe \& Bunnell } \\
\text { (2003); Dicken (2005). }\end{array}$ \\
\hline $\begin{array}{l}\text { Escola Alemã da } \\
\text { Abordagem Rela- } \\
\text { cional }\end{array}$ & $\begin{array}{l}\text { Concepções evolutivas e institucionais; Con- } \\
\text { ceituação relacional de ação analisado em } \\
\text { perspectiva espacial; Aprendizado interativo e } \\
\text { organizacional; Questões evolutivas e de ino- } \\
\text { vação. }\end{array}$ & $\begin{array}{l}\text { Bathelt \& Glückler (2002; 2003); } \\
\text { Glückler \& Bathelt (2003); Gertler } \\
\text { (1993; 1995); Grabher (1993; 2002); } \\
\text { Maskell \& Malmberg (1999); Malm- } \\
\text { berg \& Maskell (2002). }\end{array}$ \\
\hline
\end{tabular}

Fonte: Elaboração própria, a partir de Bathelt (2006)

Desta forma, o pensamento relacional foi aos poucos consolidando a GER. Bathelt e Glückler (2003) apresentaram um artigo que resume a fundamentação do que eles chamaram de segundo estágio evolutivo, porque seguiu uma transição ocorrida na Alemanha em que a Geografia Econômica contribuiu para consolidar o chamado novo paradigma da GER. A Geografia Econômica na escola Alemã foi influenciada por dois importantes paradigmas: Länderkunde (a ciência da descrição e síntese regional) e o Raumwissenschaft (Ciência Espacial), o que gerou a primeira transição. Esta fase foi fortemente influenciada pelos trabalhos de Isard $(1956,1966)$ a partir da Geografia Eco- nômica Americana (Bathelt \& Glückler, 2003).

O Quadro 3 mostra esta linha de mudanças onde o espaço deixa de ser concebido como objeto e passa a ser como perspectiva, e com isto o objeto de conhecimento, assim como a concepção de ação e teorias usadas nas pesquisas sofrem uma mudança de eixo. O objeto de pesquisa passa a ser uma descontextualização dos princípios das mudanças socioeconômicas que ocorrem no espaço, apoiado em uma epistemologia de realismo crítico e evolutivo, saindo do eixo de buscas de leis gerais explicativas ou determinísticas. 
Quadro 3 - Mudanças no design das pesquisas da Geografia Econômica Alemã

\begin{tabular}{|c|c|c|c|}
\hline $\begin{array}{c}\text { Dimensões do De- } \\
\text { sign de Pesquisa }\end{array}$ & $\begin{array}{c}\text { Geografia Econômica } \\
\text { em Länderkunde }\end{array}$ & $\begin{array}{c}\text { Ciência Geográfica (aná- } \\
\text { lise espacial) } \\
\text { Raumwissenschaft }\end{array}$ & GER \\
\hline $\begin{array}{c}\text { Concepção de Es- } \\
\text { paço }\end{array}$ & $\begin{array}{c}\text { Espaço como objeto e } \\
\text { fator causal }\end{array}$ & $\begin{array}{c}\text { Espaço como objeto e fa- } \\
\text { tor causal }\end{array}$ & $\begin{array}{c}\text { Espaço como perspectiva } \\
\text { (Geographical lens) }\end{array}$ \\
\hline $\begin{array}{c}\text { Objeto de } \\
\text { conhecimento }\end{array}$ & $\begin{array}{c}\text { Formação do espaço- } \\
\text { econômico específico } \\
\text { de uma paisagem }\end{array}$ & $\begin{array}{c}\text { Manifestação espacial } \\
\text { consequências da ação } \\
\text { (Estrutura) }\end{array}$ & $\begin{array}{c}\text { Contexto econômico das } \\
\text { relações (Processo de prá- } \\
\text { ticas sociais) }\end{array}$ \\
\hline $\begin{array}{c}\text { Concepção de } \\
\text { ação }\end{array}$ & $\begin{array}{c}\text { Determinismo ambien- } \\
\text { tal (Possibilismo) }\end{array}$ & $\begin{array}{c}\text { Atomístico: Individualismo } \\
\text { metodológico }\end{array}$ & $\begin{array}{c}\text { Relacional: Teoria de re- } \\
\text { des / Perspectiva de enrai- } \\
\text { zamento }\end{array}$ \\
\hline $\begin{array}{c}\text { Perspectiva epis- } \\
\text { temológica }\end{array}$ & $\begin{array}{c}\text { Realismo/Naturalismo } \\
\text { Objetivo de } \\
\text { pesquisa }\end{array}$ & $\begin{array}{c}\text { Neo-positivismo / Racion- } \\
\text { alismo crítico }\end{array}$ & $\begin{array}{c}\text { Realismo crítico/ Perspec- } \\
\text { tiva evolutiva }\end{array}$ \\
\hline fica da natureza da pai- \\
sagem & $\begin{array}{c}\text { Descobrimento de leis es- } \\
\text { paciais do comporta- } \\
\text { mento econômico }\end{array}$ & $\begin{array}{c}\text { Descontextualizarão dos } \\
\text { princípios das mudanças } \\
\text { socioeconômicas na pers- } \\
\text { pectiva espacial }\end{array}$ \\
\hline
\end{tabular}

Fonte: Bathelt \& Glückler (2003)

A partir das mudanças explicitadas no Quadro 3, seguiu-se dando corpo ao segundo estágio evolutivo nas pesquisas de GER. Bathelt e Glückler (2003), baseados no trabalho de Storper (1997), introduziram quatro núcleos de conceitos ou íons (segundo nomenclatura dos autores) para a análise na Geografia Econômica: Organização, Evolução, Inovação e Interação. Nesta reformulação, Storper (1997) conceituou a chamada "Santíssima Trindade" (Holy Trinity): Tecnologia, Organização e Território, que serviu de ponto de partida para o paradigma de GER proposto por Bathelt e Glückler (2003).

Assim, nesta segunda fase da GER, como se pode ver no Quadro 3, cinco dimensões são destacadas: Concepção de espaço (espaço como perspectiva); Objeto do conhecimento (contexto das relações econômicas processo de práticas sociais); Concepção de ação (teoria de redes e de enraizamento; Perspectiva epistemológica (perspectiva evolutiva) e Objetivo de pesquisa (Descontextualizarão dos princípios de mudanças socioeconômicas na perspectiva espacial - ou seja, alteração do pensamento explicativo das um danças socioeconômicas baseado na perspectiva espacial) (Bathelt \& Glückler, 2003).

Apesar dos pesquisadores reconhecerem que o contexto atua sobre a ação econômica e apresentarem estudos voltados à dinâmica dos espaços dentro do "Pensamento Relacional" (Bathelt, 2006), ainda sim, poucos pesquisadores conceituam diretamente a GER, nos trabalhos publicados atualmente. A maioria dos trabalhos especifica fundamentos, bases epistemológicas e origens usando diferentes concepções e teorias das quais derivam suas análises relacionais. Isto reforça a crítica que persiste sobre esta perspectiva, de que a noção do relacional possui alto teor de abstração (Sunley, 2008; Sanz-Ibáñez \& Antón Clavé, 2014). A maioria dos autores se referem como pensamento relacional, perspectiva relacional ou abordagens relacionais, mas coincidem na ideia de que o objeto da GER é a dinâmica das relações, a qual deve estar incluída na noção de espaço. O Quadro 4 apresenta uma breve síntese de como os autores tem expressado o pensamento relacional. 
Quadro 4 - Definições do Pensamento Relacional

\begin{tabular}{|c|c|}
\hline Definições & Autores \\
\hline $\begin{array}{l}\text { O Relacional se refere a um modo específico de coordenação econômica ou de gover- } \\
\text { nança que é baseado em laços fortes e de longo prazo, com relações recíprocas. Normal- } \\
\text { mente, essas relações são descritas como informal, face a face, colaborativas e coopera- } \\
\text { tivas, caracterizando-se pela troca de conhecimentos e um alto grau de confiança mútua. }\end{array}$ & $\begin{array}{l}\text { Dyer \& Singh (1998); } \\
\text { Capello \& Faggian } \\
\text { (2005); Jones, Hesterly } \\
\text { \& Borgatti (1997); Rut- } \\
\text { ten (2004) }\end{array}$ \\
\hline $\begin{array}{l}\text { A abordagem relacional é uma forma de ligação entre a investigação cultural e o foco } \\
\text { econômico. }\end{array}$ & Ettlinger (2001) \\
\hline $\begin{array}{l}\text { A análise relacional não é um quadro analítico rígido ou um prospecto explícito para futu- } \\
\text { ras pesquisas; mas, é uma metodologia e um ponto de partida para o trabalho empírico. }\end{array}$ & $\begin{array}{l}\text { Dicken, Kelly, Olds \& } \\
\text { Yeung (2001) }\end{array}$ \\
\hline A perspectiva relacional é um ponto de partida conceitual. & $\begin{array}{l}\text { Dicken \& Malmberg } \\
\text { (2001) }\end{array}$ \\
\hline $\begin{array}{l}\text { A perspectiva relacional tem como unidade de análise básica os atores e a dinâmica dos } \\
\text { processos de mudanças e de desenvolvimento que são ocasionados por suas relações. }\end{array}$ & Boggs \& Rantisi (2003) \\
\hline $\begin{array}{l}\text { A GER não é uma teoria padrão única, mas mais de uma maneira de ver o espaço. O ponto } \\
\text { de vista relacional repousa sobre os pressupostos do contexto, path-dependência, e a } \\
\text { contingência da ação econômica. O objetivo é descobrir uma nova maneira para ajudar a } \\
\text { formular questões de pesquisa em geografia econômica diferentes daquelas usadas em } \\
\text { ciência Regional tradicional produzindo respostas posteriormente diferentes. }\end{array}$ & $\begin{array}{l}\text { Bathelt \& Glücker } \\
(2003)\end{array}$ \\
\hline $\begin{array}{l}\text { A GER integra o econômico e social, aspectos culturais, institucionais e políticos da ação } \\
\text { humana. }\end{array}$ & $\begin{array}{l}\text { Bathelt \& Glückler } \\
\text { (2003) }\end{array}$ \\
\hline $\begin{array}{l}\text { A Perspectiva Relacional na geografia econômica é particularmente adequada para con- } \\
\text { ceituar a ação econômica e política na perspectiva espacial. Em oposição à visão tradicio- } \\
\text { nal, esta abordagem nos permite analisar as consequências de interdependências globais } \\
\text { e sua relação aos processos de concentração local e especialização. }\end{array}$ & $\begin{array}{l}\text { Bathelt (2003; 2005a; } \\
\text { 2005b; 2006) }\end{array}$ \\
\hline $\begin{array}{l}\text { A GER não é um quadro analítico cuidadosamente definido; é } \\
\text { teorias e ideias que compartilham algumas características e dife }\end{array}$ & Bathelt (2006) \\
\hline $\begin{array}{l}\text { A Perspectiva Relacional se baseia em uma abordagem a nível micro, focando os atores } \\
\text { naqueles processos econômicos e sociais que resultam em aglomeração, especialização } \\
\text { econômica, desenvolvimento desigual. }\end{array}$ & Bathelt (2006) \\
\hline $\begin{array}{l}\text { A GER está preocupada com o social e espacial, a divisão e integração do trabalho, com o } \\
\text { impacto positivo e negativo de estruturas históricas, processos e eventos sobre as deci- } \\
\text { sões de hoje, como os processos de criação de conhecimento e à difusão e os efeitos da } \\
\text { mudança tecnológica; e, por último com as interações entre os agentes econômicos e as } \\
\text { instituições formais e informais que estimulam e os restringem. }\end{array}$ & $\begin{array}{l}\text { Bathelt \& Glückler } \\
(2003,2011)\end{array}$ \\
\hline $\begin{array}{l}\text { Perspectivas Relacionais são com base em abordagens micro-nível, focando atores envol- } \\
\text { vidos nos processos econômicos e sociais que resultam em resultados desiguais, tais como } \\
\text { níveis de aglomeração, especialização econômica ou desenvolvimento. }\end{array}$ & $\begin{array}{l}\text { Barrutia, Echebarria, } \\
\text { Hartmann, Apaolaza- } \\
\text { lbáñez (2013) }\end{array}$ \\
\hline $\begin{array}{l}\text { O contraponto da perspectiva relacional fornece uma adequada analogia espacial para } \\
\text { conceituar cidades pelo nível de seus relacionamentos. Conceitua as relações urbanas, de } \\
\text { ambas as formas ligadas e fragmentadas, portanto, conceber cidades de acordo com a } \\
\text { aleatoriedade espacial e temporal de um modo inerente que coloca em primeiro plano as } \\
\text { rupturas e as assimetrias de fragmentos complexos em vez de lisas totalidades. }\end{array}$ & O'Callaghan (2012) \\
\hline
\end{tabular}

Fonte: Elaboração própria

Segundo Bathelt e Glückler (2003), o objetivo de pesquisa na GER está alicerçado em três principais proposições:

$\checkmark$ Contexto-A partir de uma perspectiva estrutural, os agentes econômicos estão imersos em um ambiente de relações sociais e espaciais específicos (Granovetter,
1985);

$\checkmark$ Dependência da Trajetória - A partir de uma perspectiva dinâmica, a contextualização cria uma dependência da trajetória, pois as ações de ontem, condicionam/direcionam as ações futuras (Nelson \& Winter, 1982); 
Contingência - Ações econômicas são sistemas abertos e muitas vezes não previsíveis (Sayer, 1992). A ação econômica parte da ação humana e nem sempre segue padrões pré-estabelecidos havendo um algo grau de contingência.

Assim, fundamentalmente a GER analisa o espaço partindo das relações que a ação humana gera nos sistemas de produção e esta influência sobre a organização e o desenvolvimento territorial. Sanz-lbáñez e Antón Clavé (2014), baseados em Bathelt e Glückler (2011) e Storper (1997), salientam que a GER focaliza na: organização: preocupação com o social e espacial, com a divisão e integração do trabalho; evolução: impactos positivos e negativos de estruturas históricas, processos e eventos nas decisões atuais; inovação: processos de criação de conhecimento e difusão, bem como os efeitos das mudanças tecnológicas; interação: as interações entre os agentes econômicos e as instituições formais e informais.

Um ponto chave para o desenvolvimento do turismo como atividade econômica é o empreendedorismo. Vale, Amâncio e Lima (2006) consideram três categorias de empreendedores relacionados a redes organizacionais ou aglomerações produtivas: empreendedor clássico (modelo de empresa in- dependente), o empreendedor coletivo utilitarista (ação em rede setorial de objetivo único) e o empreendedor coletivo setorial (ação em rede setorial de objetivos múltiplos). O turismo é uma atividade em que pode ser obtido um melhor desempenho baseado em uma postura de empreendedores coletivos setoriais. A ação de empreender é uma ação humana, contextualizada e contingente, que a partir dos quatro íons definidos por Bathelt e Glückler (2003) - Inovação, Organização, Interação, e Evolução, gera a ação econômica para o desenvolvimento territorial. Além disso, a ciência econômica identifica o empreendedorismo como um elemento vital para o desenvolvimento, e em Schumpeter (1961) o empreendedor assume um papel de protagonista da evolução econômica.

Nesta ordem, o espaço como entidade socialmente construída pela ação humana se traduz em uma ação econômica. 0 contexto econômico das relações é o processo de práticas sociais (intenções, estratégias e práticas dos atores) que é o objeto de conhecimento da GER (Butler, 2003). A Figura 1 indica a transição do pensamento relacional em direção ao paradigma de GER pela proposição de Bathelt e Glückler (2003).

Figura 1- Proposição da Geografia Econômica Relacional (GER)

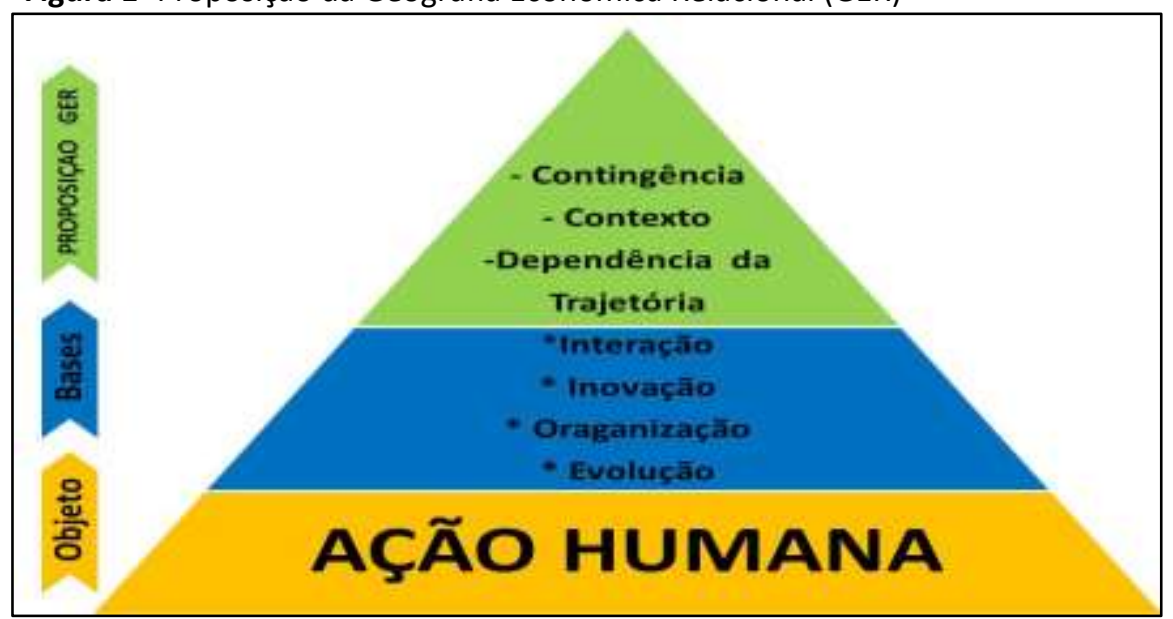

Fonte: Elaboração própria 
A ação humana ganha destaque, pois cria ou limita as oportunidades. Esta ação ocorre em um espaço que acumulou conhecimento, hábitos e outros elementos que influenciam nas decisões futuras, ou seja, existe uma dependência da trajetória. Porém, este conjunto (ação humana + contexto + dependência da trajetória) ainda sofre outra influência que é a contingência da própria ação humana e do contexto, já que a ação econômica nem sempre é previsível (Bathelt \& Glückler, 2011; Sanz-Ibáñez \& Antón Clavé, 2014).

\section{DESTINOS TURÍSTICOS ANALISADOS COMO AGLOMERAÇÕES PRODUTIVAS (REDES, DISTRITOS, CLUSTER, APL) SOB A ÓTICA DA GER}

É consensual entre os pesquisadores que o turismo é uma atividade espacial, socialmente construída, portanto, evolui (Seaton \& Bennett, 1996; Ringer, 1998; Saarinen, 2001; Shaw \& Williams, 2004). Igualmente, é aceito que a formação de algum tipo de rede organizacional na atividade turística, assim como de mecanismos de governança, é uma prática usual nos destinos turísticos para apoiar o desenvolvimento local (Della Corte \& Sciarelli, 2012).

O destino turístico acumula funções econômicas e sociais, possuindo alta complexidade e interdependência entre os atores com grande diversidade compondo a atividade turística. A análise da forma operacional do destino turístico, sua tipologia de aglomeração produtiva, contribui para desenvolver instrumentos de planejamento e gestão mais adequados à realidade local e regional, portanto, melhorando o nível de distribuição dos benefícios da atividade turística e a sustentabilidade de uso dos recursos disponíveis (Buhalis, 2000).

Os estudos para interpretar a evolução e rendimento dos destinos desenvolvidos utilizando os modelos convencionais em geografia do turismo têm evidenciado as debilidades destes modelos como ferramentas explicativas indicando a necessidade de uma nova categorização e perspectiva de análise (Brouder \& Eriksson, 2013; Williams, 2013; Sanz-Ibánez \& Antón Clavé, 2014).

Um destino turístico pode se organizar de diferentes formas, representando uma aglomeração produtiva, vista a existência de uma co-localização que converte a sinergia gerada em vantagens competitivas (Costa \& Souto-Maior, 2006). É importante explicitar o limiar entre algumas tipologias como redes, distritos, cluster, e os arranjos produtivos locais (APLS), para verificar se a GER pode substituir a análise de destinos turísticos realizados a partir destas tipologias de aglomerações ou se a GER é complementar a estas análises.

O destino turístico é comumente visto como um conjunto de instituições e atores localizados em um espaço físico ou virtual em que as relações desafiam a tradicional dicotomia de produção-consumo. O destino é uma unidade de ação e produção, onde vários stakeholders interagem produzindo a experiência turística (Saraniemi \& Kylänen, 2010; Pearce, 2014). Nos estudos de turismo se utiliza seguidamente o termo aglomeração, pois o desenvolvimento desta atividade a nível micro gera um número de empresas próximas territorialmente que muitas vezes 
se articulam buscando o desenvolvimento da atividade. As origens desta classificação se encontram em Porter (1999), que define aglomeração como um agrupamento geograficamente concentrado de empresas interrelacionadas e instituições correlacionadas numa determinada área, vinculadas por elementos comuns e complementares, ou seja, as aglomerações turísticas são o que Porter consagrou na terminologia de cluster. No entanto, de uma forma abrangente devido à própria definição de aglomeração produtiva, também se tem incluído nos estudos de aglomerações os distritos industriais e os arranjos produtivos locais (APLS).

O limiar entre redes, distritos, clusters e APLs é, por vezes, difícil de estabelecer. A linha tênue entre uma aglomeração e um cluster pode ser considerada a concentração geográfica e setorial mais acentuada que os clusters têm frente às aglomerações produtivas, e a melhor capacidade coletiva para lidar com o mercado (Schmitz, 1997; Silva, 2014). Um APL é considerado uma aglomeração de organizações, com grande número de pequenas empresas, que utilizam uma ação conjunta, cooperando para alcançar melhor competitividade e desenvolvimento (Pyke \& Sengenberger, 1993; Caporali \& Volker, 2004; Costa et al, 2012).

Por outro lado, Dini (1997) distingue distritos industriais de redes porque considera que as redes têm um número limitado de empresas, participantes claramente identificados e uma composição que varia pouco, além do que os participantes não necessariamente estão no mesmo território. Especialmente, quando estamos analisando destinos turísticos como um todo, é preciso destacar o caráter excludente que as redes possuem. A Organização das Nações Unidas para o Desenvolvimento conceitua uma rede empresarial como uma aliança estratégica permanente entre um grupo limitado e claramente definido de empresas independentes, as quais colaboram para alcançar objetivos comuns de médio e longo prazo, orientadas em direção ao desenvolvimento da competitividade dos participantes (ONUDI, 1999). Neste sentido, uma rede é um conjunto de sócios preferenciais, selecionados, portanto, com caráter excludente, que não se aplica a uma análise de destino turístico considerando sua integralidade (Camagni, 1991; Ceglie et al, 1999).

Por outro lado, os estudos teóricoempíricos sobre distritos tem sido foco de pesquisadores desde os anos 70 , período que uma grande recessão econômica levou vários países a buscar soluções em que muitas delas se basearam em formação de distritos industriais (Pyke et al, 1990). Nesta perspectiva, temos organizações localizadas em área geograficamente definida (co-localização), um grande número de empresas com diversas formas e tamanhos participando das distintas etapas produtivas para a formação de um produto homogêneo (Pyke et al, 1990). Outro grande fator que aproxima os destinos de distritos é a massiva participação de empresas de pequeno porte, característica salientada por diversos autores da tipologia de distritos (Hjalager, 2000). Adicionalmente, duas características destacadas na teorização de distritos aproximam ainda mais este enquadramento para destinos turísticos: a existência de instituições públicas e privadas locais que apoiem os agentes econômicos e a exis- 
tência de um entorno cultural e social comum que vincule estes agentes econômicos, gerando códigos de comportamento comuns (Pyke et al, 1990).

Hjalager (2000) foi uma das autoras que contribuiu para o estabelecimento da tipologia "Distritos Turísticos". Seu trabalho identifica cinco determinantes para qualificar um distrito turístico: existência de interdependência entre as empresas; limites flexíveis das firmas; existência de competição cooperativa; confiança na colaboração sustentada; cultura de comunidade com políticas públicas de apoio. Igualmente à perspectiva de redes, os distritos turísticos como arranjo espacial produtivo também apresentam em sua base fundamentos da GER.

O caráter associativo de empresa cooperando em busca da competitividade é explicitamente matéria inclusa no pensamento relacional, assim como, o aprendizado coletivo gerado pelo grupo que leva a uma dependência da trajetória e a circunscrição em um espaço definido coloca os participantes em um particular contexto (Bathelt, 2006).

Se acentuam algumas características que favorecem a releitura desta realidade produtiva através da GER. A existência da colocalização é apontada pelos autores de GER como um facilitador relacional (Bathelt, 2006). O fato dos agentes estarem sujeitos a um contexto especial que os leva a operar sob condições institucionais e sociais específicas das quais eles não podem ser facilmente separados também é prevista dentro da abordagem GER (Polanyi, 1957; Granovetter, 1985). Concretamente, o atendimento aos cinco determinantes que Hjalager (2000) prevê para a tipologia de distritos turísticos permite o que Amin e Cohendet (2004), dentro do pensamento relacional, apontam como a proximidade relacional que fecha a interação social e transforma-a em uma fonte de competitividade.

A classificação como cluster merece uma atenção especial, pois este construto gerou uma das formas produtivas mais estudadas. Este conceito definido por Porter (1988) encontra um grande problema prático na atividade turística. A atividade dentro do destino é difusa, gerando uma imprecisão de medida da agrupação e categorização, deixando dúvidas se estamos frente a um cluster turístico (Amato, 1999; Ivars Baidal et al, 2014). No entanto, o modelo territorialista e endógeno de desenvolvimento regional, ainda é considerado como o mais apropriado, podendo-se eleger a especialização produtiva (turismo) como um elemento representativo das explicações do desenvolvimento econômico de base local e regional (Silva, 2006).

Esta imprecisão tem levado ao uso do termo cluster de forma geral, indistintamente para qualquer tipo de arranjo produtivo, e especialmente confundindo-o com distrito. As duas formas têm semelhanças, mas em cluster é necessário haver um grau concentração geográfica, o que em destinos turísticos nem sempre ocorre. A medida mais utilizada para verificar esta concentração tem sido o Quociente Locacional (QL) e o número de empregos gerados para definir a importância da atividade para a região analisada.

No entanto, não há na literatura uma precisão de quanto este coeficiente deve ser para que a atividade turística seja considera- 
da como um cluster. Outro fato que pesa nesta perspectiva se encontra destacado por Amato (1999) que é a dificuldade de "clusterização", pois é uma cadeia produtiva composta de uma série de serviços complementares aos produtos turísticos principais, tornando ainda mais difícil separar claramente as categorias ou aglomerados (clusterização).

Ivars Baidal et al. (2014), destacam que esta configuração exige condições prévias, entre elas: políticas regionais ou de inovação, iniciativas de empresa ou associações, existência de um projeto aglutinador, ou de uma pessoa com capacidade de liderança e mobilização. De qualquer forma, a perspectiva de cluster está baseada numa eficiência coletiva (Porter, 1988) gerada a partir do inter-relacionamento entre os agentes, circunscritos em um espaço geográfico. Temos uma coincidência com a perspectiva de GER, pois o papel das relações assume condição fundamental para a obtenção desta eficiência coletiva.

Abordando por APLs, o território passa a ter um recorte específico de análise e ação, onde ocorre o processo produtivo, inovador e de cooperação (Cassiolato, Lastres \& Maciel, 2013). Esta tipologia de aglomeração tem um importante grau de enraizamento, pode ter diferentes formas de governança, e é fonte de geração e compartilhamento de conhecimentos, proporcionando dinamismo e inovação a região em que esta instalada (Silva, 2014). Hoffmann e Campos (2013) destacam quatro recursos que se formam dentro dos APLs e que têm sido muito discutidos teoricamente: a confiança, a mão-de- obra qualificada, a cooperação e o papel das instituições. $O$ que desde uma perspectiva do pensamento relacional é ação humana no seu contexto gerando a ação econômica (Bathelt, 2006). Assim, a GER pode oferecer um ângulo para que se estude o somatório da ação destes recursos na dimensão territorial e o reflexo desta ação humana na competitividade local.

O Quadro 5 apresenta algumas características de um destino turístico considerando se as mesmas são atendidas na análise através das diferentes formas de aglomerações produtivas discutidas neste artigo, bem como se a GER possibilitaria atender tais características, levando em conta os fundamentos teóricos da GER aplicados para a análise de destinos turísticos.

Observa-se que existe a necessidade de adaptar para o turismo alguns conceitos tradicionais de aglomeração, redes, distrito, cluster ou agrupamento, e de traduzir algumas teorias à prática dos destinos turísticos, especialmente dar limites claros quanto à agrupação (clusterização) e a conformação de distritos (Judd, 1995; Weidenfeld, Butler \& Williams, 2010; Sanz-Ibáñez \& Antón Clavé, 2014). Diante do exposto, se pode afirmar que é visível a contribuição da GER na análise dos destinos turísticos. Mas as questões que persistem são: A GER substitui a perspectiva de redes, distritos, clusters e arranjos ou ela a complementa? A GER pode ser aplicada em qualquer um destes arranjos produtivos ou existem limitações? 
Quadro 5 - Características analisadas nos destinos turísticos pelas diferentes perspectivas.

\begin{tabular}{|l|c|c|c|c|c|}
\hline \multicolumn{1}{|c|}{ Características nos Destinos Turísticos } & Rede & $\begin{array}{c}\text { Dis- } \\
\text { trito }\end{array}$ & $\begin{array}{c}\text { Clus- } \\
\text { ter }\end{array}$ & APL & GER \\
\hline Amplos limites geográficos & & $\mathrm{X}$ & & & $\mathrm{X}$ \\
\hline Existência de proximidade relacional & $\mathrm{X}$ & $\mathrm{X}$ & $\mathrm{X}$ & $\mathrm{X}$ & $\mathrm{X}$ \\
\hline Interdependência entre as organizações & $\mathrm{X}$ & $\mathrm{X}$ & $\mathrm{X}$ & $\mathrm{X}$ & $\mathrm{X}$ \\
\hline Existência de um objetivo Comum & $\mathrm{X}$ & & & $\mathrm{X}$ & $\mathrm{X}$ \\
\hline Presença de organizações de Governança & $\mathrm{X}$ & & & $\mathrm{X}$ & $\mathrm{X}$ \\
\hline Dependência da infraestrutura e serviços urbanos & $\mathrm{X}$ & $\mathrm{X}$ & $\mathrm{X}$ & $\mathrm{X}$ & $\mathrm{X}$ \\
\hline Alta dependência do recurso local (natural e cultural) & & $\mathrm{X}$ & & $\mathrm{X}$ & $\mathrm{X}$ \\
\hline $\begin{array}{l}\text { Dependência da afinidade por parte da população local } \\
\text { com a atividade }\end{array}$ & & & & & $\mathrm{X}$ \\
\hline Nível análise micro/meso & $\mathrm{X}$ & $\mathrm{X}$ & $\mathrm{X}$ & $\mathrm{X}$ & $\mathrm{X}$ \\
\hline Alta dependência da atmosfera e meio social & & $\mathrm{X}$ & & $\mathrm{X}$ & $\mathrm{X}$ \\
\hline Dependência da trajetória & & & & $\mathrm{X}$ & $\mathrm{X}$ \\
\hline Existência de co-criação de experiências & & & & $\mathrm{X}$ & $\mathrm{X}$ \\
\hline Alto grau de heterogeneidade de atividades econômicas & & $\mathrm{X}$ & $\mathrm{X}$ & $\mathrm{X}$ & $\mathrm{X}$ \\
\hline $\begin{array}{l}\text { Seleção de participantes com caráter inclusivo (aberto a } \\
\text { todos do destino) }\end{array}$ & & $\mathrm{X}$ & & & $\mathrm{X}$ \\
\hline Não hierárquico & & $\mathrm{X}$ & $\mathrm{X}$ & & $\mathrm{X}$ \\
\hline Produto final único (Destino Turístico) & & & & $\mathrm{X}$ & $\mathrm{X}$ \\
\hline $\begin{array}{l}\text { Existência de Instituições públicas e políticas de apoio } \\
\text { aos agentes econômicos }\end{array}$ & & $\mathrm{X}$ & $\mathrm{X}$ & & $\mathrm{X}$ \\
\hline $\begin{array}{l}\text { Alto grau de existência de cultura comum entre os agen- } \\
\text { tes }\end{array}$ & & $\mathrm{X}$ & $\mathrm{X}$ & $\mathrm{X}$ & $\mathrm{X}$ \\
\hline Existência de cooperação-competitiva & & $\mathrm{X}$ & $\mathrm{X}$ & $\mathrm{X}$ & $\mathrm{X}$ \\
\hline Formas de arranjo espacial e concentração variada & & & & & $\mathrm{X}$ \\
\hline Alta participação de PYMES & $\mathrm{X}$ & $\mathrm{X}$ & $\mathrm{X}$ & $\mathrm{X}$ & $\mathrm{X}$ \\
\hline Ações ou marketing e promoção em conjunto & $\mathrm{X}$ & $\mathrm{X}$ & $\mathrm{X}$ & $\mathrm{X}$ \\
\hline Organização empresarial e social & & $\mathrm{X}$ & $\mathrm{X}$ & $\mathrm{X}$ & $\mathrm{X}$ \\
\hline Contexto & & & $\mathrm{X}$ \\
\hline Evolução & & $\mathrm{X}$ & $\mathrm{X}$ \\
\hline Formação/facilitador de inovação & & & $\mathrm{X}$ & $\mathrm{X}$ \\
\hline
\end{tabular}

Fonte: Elaboração própria

Se extrai do Quadro 5 que quanto mais a forma de análise do destino tende a escala micro, melhor o atendimento das características do destino turístico como produto integral. Além disso, a GER demonstra que pode incluir todas as características presentes em destinos turísticos possibilitando uma análise mais completa.

Alguns autores têm buscado uma tipologia própria de aglomeração para o turis- mo, cunhando alguns termos e definições como: Distritos Turísticos (Hjalager, 2000; Baggio, 2008); Cluster Turístico (Costa et al, 2012); Sistema Turístico Local (Capone, 2004, 2006; Maulet, 2006; Lazzeretti; Capone, 2008); ou Destino Turístico Dinâmico (SanzIbáñez \& Antón Clavé, 2014). Assim, observase que os destinos turísticos caminham em uma direção a obter sua própria tipologia, sua própria identidade como arranjo produ- 
tivo e unidade de análise espacial, a qual indica ser uma mescla de redes, distritos, cluster e APLs, porém, que certamente está calçada no pensamento relacional, pois configura uma rede de relações entre atores que competem entre si pela divisão do mercado, mas cooperam para desenvolvê-lo (Della Corte \& Sciarelli, 2012).

As clássicas análises de destinos se baseiam em modelos de competitividade turísticas como o de Porter, 1990; Dwyer e Kim, 2003; Ritchie e Crouch, 2003, bem como as análises por recursos e capacidades baseadas em Barney (1989), e as por aglomerações produtivas. No entanto, estas perspectivas de análise se defrontam com o desafio de incluir de forma mais contundente as relações entre os diversos atores que formam este subsetor.

As relações de cooperação-competitiva (coopetição) interna e externa ao destino turístico conduzem a melhoria da eficiência coletiva, a formação das regiões de aprendizado e inovação (Ivars Baidal et al, 2014), mas, neste sentido, uma tipologia de sistemas produtivos para os destinos turísticos ainda não está claramente definida.

Complementando as discussões anteriores, cabe destacar que Pearce (2014) recentemente propôs um marco conceitual integral para destinos turísticos, construindo sua proposta entre distritos industriais, redes, clusters, sistemas e estruturas sociais. Sua proposição integra a dimensão geográfica (espaço e lugar), os modos de produção (estrutura, comportamento e atores) e a dimensão dinâmica (estrutura e fatores de condução). Particularmente, o autor ressalta que a relação entre estas dimensões e seus fatores gera a complexidade, adaptabilidade e evolução dos destinos. Apesar de que o próprio autor declara que ainda falta muito em termos de refinar cada um dos elementos que compõe sua proposta, ele reforça que é um caminho que se aponta para uma classificação própria para destinos turísticos (Pearce, 2014), e que, como se pode ver, transita pelos fundamentos da Geografia Econômica Evolutiva e Relacional.

\section{DISCUSSÃO}

Os argumentos e fundamentos expostos demonstram que a análise relacional é necessária para estudos econômicos regionais ou locais, e especialmente para os estudos de destinos turísticos. A GER tem em seu centro a ação humana, e se fundamenta na contingência, contexto e dependência da trajetória, a qual esta baseada nos íons de interação, inovação, organização e evolução. Estes elementos conformam o empreendedorismo, que gera a ação econômica imersa em um ambiente de coopetição para a formação e desenvolvimento do destino turístico como produto integral. O somatório destas considerações indica uma integração destes conhecimentos através do uso da GER para as análises regionais.

A ação humana permeia e forma os fundamentos da GER que suportam a formação e evolução do destino turístico integrado. Porém, a forma como a GER se concretizará no planejamento do destino, como instrumento de análise e ferramenta capaz de gerar subsídios à tomada de decisão, 
ainda é um ponto não definido. A compreensão das relações de coopetição pode ser uma forma de analisar o destino turístico considerando as perspectivas da GER e possibilitando o desenvolvimento de ferramentas para a análise empírica relacional. Esta forma de comportamento se calça na formação de redes de valores que incluem os concorrentes, complementários, clientes e fornecedores (Brandenburg \& Nalebuff, 1996).

Outra questão que esta discussão traz à tona é que os fundamentos da GER interagem entre si, atuando na formação deles próprios, sendo um ciclo em que não se identifica sua gênese. $O$ destino turístico ao se formar a partir da existência de recursos naturais, culturais, sociais, políticos e econômicos, condiciona uma contextualização e uma trajetória que por sua vez condiciona a ação humana. Mas, esta ordem de formação pode ser ao contrário?

Igualmente, se questiona se a GER deve ser usada como um novo paradigma concorrente na análise de destinos turísticos ou se deve ser considerado como um paradigma complementar aos existentes; e de que forma este complemento poderá ser inserido nas análises teórico-empíricas para que não se sobreponham ao conhecimento, mas sim se agregue. Por último, se questiona se seria o caso de revisão das teorias consolidadas, como por exemplo, para reformular suas bases teóricas incluindo as relações sociais.

Estes questionamentos seguem quase a mesma linha indicada nas inúmeras críticas que a GER vem sofrendo, o que indica que apesar de seu aclamado uso, sua evolução em direção a uma teoria consolidada não tem ocorrido. Igual situação ocorre com os conceitos de aglomerações como cluster/distrito/redes/APLs que continuam a receber críticas pela tênue linha que os separa e a falta de critério claro para diferenciar estas tipologias e aplicá-las na análise de destinos turísticos.

Independente de ainda não haver uma clareza quanto a melhor forma de enquadramento do destino turístico enquanto a sua tipologia de aglomeração, se observa que a GER pode ser utilizada para analisar os destinos seja qual for a sua forma de organização produtiva, pois todas as características dos destinos são abarcadas desde uma perspectiva GER. Além disso, o objeto de análise passa a ser a ação humana e suas relações, e estas ocorrem independentemente da forma de aglomeração produtiva considerada.

\section{CONSIDERAÇÕES FINAIS}

Este artigo analisou criticamente o pensamento relacional, trazendo ao debate acadêmico a proposta da GER, sua origem e fundamentação, com o objetivo de incitar a comunidade científica a unir-se ao esforço de desenvolver uma metodologia de análise e aplicação empírica que viabilize o uso deste enfoque. Este estudo realizou uma compilação de artigos e apresenta uma consistente revisão de literatura sobre a teoria relacional, articulando estes conceitos com a atividade turística. Discutiu-se o uso de GER em estudos de destinos turísticos, pois este subsetor possui particularidades baseadas na interdependência dos atores para constituir o destino turístico como produto integral (Della Corte \& Sciarelli, 2012). 
Não se poderia deixar de trazer ao debate alguns pontos críticos da GER que estão apontados no trabalho desenvolvido por Sanz-Ibáñez e Antón Clavé (2014) de forma muito esclarecedora, entre eles: a falta de especificidade e a abstração extrema apontada por Sunley (2008); a pouca teorização sobre as relações de poder (Yeung, 2005); o foco sobre empresas em lugar dos indivíduos na análise em nível micro (Ettlinger, 2003); e a baixa ênfase nas relações e fluxos não locais (Yeung, 2005).

Por outro lado, cabe destacar que vários autores têm trabalhado dentro de perspectivas relacionais. O papel da interação local e global entre os atores econômicos e não econômicos sem dúvida é um fator que vem a contribuir com a prosperidade dos lugares ou com o atraso no seu desenvolvimento (Bathelt \& Glückler, 2011).

Tudo indica que a GER pode contribuir na análise dos destinos turísticos, porém precisa desenvolver mais profundidade na sua fundamentação, ferramentas de análise e metodologias próprias, para que esta difusa perspectiva ganhe um direcionamento que a conduza ao status de um paradigma e então, gere uma contribuição efetiva na análise regional e local bem como um apoio gerencial a políticas públicas. Outra contribuição sobre um tema ainda sem consenso entre os acadêmicos do turismo que poderá vir da GER é o estabelecimento de uma tipologia de aglomeração produtiva com características claras quanto a sua forma de classificação, trazendo luz às dúvidas se consideramos o destino sobre a perspectiva de rede, distrito, cluster, ou APL.

A ação empreendedora gerada a par- tir dos quatro íons definidos por Bathelt e Glückler (2003) - Inovação, Organização, Interação, e Evolução, cujo ápice se faz pela ação humana calcado nos fundamentos da GER (contexto, contingência e dependência da trajetória) produz um sistema de coopetição que pode conduzir a competitividade regional.

Porém, se é o contexto que forma e desenvolve o destino turístico ou se é o destino que forma a contextualização, sendo a ação humana e a dependência da trajetória reflexos deste contexto, são as questões futuras que a GER precisa aprofundar para os estudos turísticos. Ao que tudo indica é um ciclo que pode ser começado a partir de qualquer ponto, dependendo da condição prévia, política, natural, econômica e social, que o ambiente oferece.

Assim, para finalizar, indica-se que a partir do pensamento relacional a comunidade acadêmica acentue os trabalhos na direção de estabelecer uma tipologia com critérios próprios para classificação e análise dos destinos turísticos, de forma a estabelecer mecanismos para sua aplicação prática. Isto pode ser feito adaptando a partir das diversas teorias consagradas no setor industrial e da economia, ou criando novas formas, mas tendo em mente as particularidades da atividade turística.

Assim, considera-se que a GER pode ser usada para analisar um destino turístico sob qualquer forma de aglomeração, pois possui o espaço como perspectiva e não como objeto ou fator causal. Isto quer dizer que o objeto de conhecimento é o contexto econômico das relações, fato que ocorre em qualquer arranjo produtivo. Enfim, conclui-se 
que a GER pode vir a ser uma base teórica para que se criem as ferramentas de análise, classificação e monitores que verifiquem a influência da proximidade relacional e seus reflexos no desenvolvimento das localidades e regiões. Estas ferramentas podem contribuir duplamente: para tirar a GER da abstração que se encontra e para dar corpo a uma nova teorização aplicada ao turismo.

\section{REFERÊNCIAS}

Allen, J. (1997). Economies of power and space. Geographies of economies, London, New York, Sidney: Arnold 59-70.

Amin, A. (ed) (1994). Post-Fordismo. Oxford. Cambridge: MA Blackwell.

Amin, A. (1998). Globalisation and regional development: a relational perspective. Competition \& Change, 3(1-2), 145-165.

Amin, A., \& Cohendet, P. (2004). Architectures of knowledge: Firms, capabilities, and communities. Oxford University Press on Demand.

Amin, A., \& Thrift, N. (2000). What kind of economic theory for what kind of economic geography? Antipode, 32(1), 4-9.

Amin, A.; Massey, D. \& Thrift, N. (2003). Decentering the national: a radical approach to regional inequality. London: Catalyst.

Baggio, R. (2008). Network analysis of a tourism destination (Unpublished doctoral dissertation). Australia: University of Queensland.

Barney, J. (1991). Firm resources and sustained competitive advantage. Journal of management, 17(1), 99-120.

Barrutia, J. M., Echebarria, C., Apaolaza-Ibáñez, V., \& Hartmann, P. (2014). Informal and formal sources of knowledge as drivers of regional innovation: digging a little further into complexity. Environment and Planning A, 46(2), 414-432.

Bathelt, H., \& Glückler, J. (2002). Wirtschaftsgeographie: Ökonomische Beziehungen in räumlicher Perspektive (Economic geography: Economic relations in spatial perspective). Stuttgart: UTB-Ulmer.

Bathelt, H., \& Glückler, J. (2003). Toward a relational economic geography. Journal of economic geography, 3(2), 117-144.

Bathelt, H., \& Glückler, J. (2011). The relational economy: Geographies of knowing and learning. Oxford University Press.

Bathelt, H. (2003). Geographies of production: growth regimes in spatial perspective 1-innovation, institutions and social systems. Progress in Human Geography, 27(6), 763-778.

Bathelt, H. (2005). Geographies of production: growth regimes in spatial perspective (II)knowledge creation and growth in clusters. Progress in human geography, 29(2), 204-216.

Bathelt, H. (2005). Cluster relations in the media industry: Exploring the'distanced neighbour'paradox in Leipzig. Regional Studies, 39(1), 105-127.

Bathelt, H. (2006). Geographies of production: growth regimes in spatial perspective 3-toward a relational view of economic action and policy. Progress in human geography, 30(2), 223236.

Boggs, J. S., \& Rantisi, N. M. (2003). The 'relational turn'in economic geography. Journal of economic geography, 3(2), 109-116.

Boschma, R. A., \& Frenken, K. (2006). Why is economic geography not an evolutionary science? Towards an evolutionary economic geography. Journal of economic geography, 6(3), 273302. 
Boschma, R., \& Frenken, K. (2010). The spatial evolution of innovation networks. A proximity perspective. The handbook of evolutionary economic geography, Cheltenham, UK: Edward Elgar Publishing, 120-135.

Boschma, R., \& Martin, R. (2007). Constructing an evolutionary economic geography. Journal of Economic Geography, 7(5), 537-548.

Boschma, R., \& Martin, R. (2010). The aims and scope of evolutionary economic geography. The handbook of evolutionary economic geography, 3-39.

Brandenburger, A., \& Nalebuff, B. J. (1996). CoOpetition (Currency Doubleday, New York).

Brouder, P., \& Eriksson, R. H. (2013). Tourism evolution: On the synergies of tourism studies and evolutionary economic geography. Annals of Tourism Research, 43, 370-389.

Buhalis, D. (2000). Marketing the competitive destination of the future. Tourism management, 21(1), 97-116.

Butler, R. W. (2004). The tourism area life cycle in the twenty-first century. In A. A. Lew, C. M. Hall, \& A. M. Williams (Eds.), A companion to tourism (pp. 159_169). Oxford: Blackwell.

Camagni, R. (1991). Innovation Networks: Spatial Perspectives. London: Belhaven-Pinter.

Capello, R., \& Faggian, A. (2005). Collective learning and relational capital in local innovation processes. Regional studies, 39(1), 75-87.

Capone, F. (2004). Regional competitiveness in tourist local systems. 44을 European Congress of the European Regional Science Association, Regions and Fiscal Federalism, University of Oporto.

Capone, F. (2006). Systemic approaches for the analysis of tourism destination: towards the tourist local systems. Tourism local systems and networking, 7-23.

Caporali, R., \& Volker, P. (2004). Metodologia de Desenvolvimento de Arranjos Produtivos Locais: projeto PROMOS-SEBRAE-BID versão 2.0. Brasília, Sebrae.

Ceglie, G., Clara, M., \& Dini, M. (1999). Cluster and network development projects in developing countries: lessons learned through the UNIDO experience. Boosting innovation: The cluster approach, 269-292.

Clark, G. L. (1983). Fluctuations and rigidities in local labor markets. Part 2: reinterpreting contracts. Environment and Planning A, 15(3), 365377.

Clark, G., \& Tracey, P. (2004). Global competitiveness and innovation: an agent-centred perspective. Basingstoke, New York: Palgrave Macmillan.

Coe, N. M., \& Bunnell, T. G. (2003). 'Spatializing'knowledge communities: towards a conceptualization of transnational innovation networks. Global networks, 3(4), 437-456.

Coe, N. M., Hess, M., Yeung, H. W. C., Dicken, P., \& Henderson, J. (2004). 'Globalizing'regional development: a global production networks perspective. Transactions of the Institute of British geographers, 29(4), 468-484.

Costa, H.A.; Costa, A.C. \& Miranda, N.S.J. (2012). Arranjos Produtivos Locais (APL) no Turismo: estudo sobre a Competitividade e o Desenvolvimento Local na Costa dos Corais-AL. Revista acadêmica Observatório de Inovação do Turismo, 7(1).

Davidson, R., \& Maitland, R. (1997). Tourism destinations. Hodder \& Stoughton.

Della Corte, V., \& Sciarelli, M. (2012). Can coopetition be source of competitive advantage for strategic networks. Corporate Ownership and Control, 12(1), 363-379.

Dicken, P. (2005). Tangled webs: transnational production networks and regional integration. Spatial Aspects Concerning Economic Structures Working Paper (SPACES) 2005-04, Faculty of Geography, Philipps- University of Marburg. 
Dicken, P., \& Malmberg, A. (2001). Firms in territories: a relational perspective. Economic geography, 77(4), 345-363.

Dicken, P., Kelly, P. F., Olds, K., \& Wai-Chung Yeung, H. (2001). Chains and networks, territories and scales: towards a relational framework for analysing the global economy. Global networks, 1(2), 89-112.

Dini, M. (1997). Enfoques conceptuales para el estudio de pequeñas y medianas empresas. Santiago de Chile. CEPAL.

Domareski Ruiz, T. C., Fumi Chim Miki, A., \& Gândara, J. M. (2014). A geografia econômica evolutiva como perspectiva de análise da dinâmica dos destinos turísticos. Caderno Virtual de Turismo, 14(3).

Dyer, J. H., \& Singh, H. (1998). The relational view: Cooperative strategy and sources of interorganizational competitive advantage. Academy of management review, 23(4), 660-679.

Dwyer, L., \& Kim, C. (2003). Destination competitiveness: determinants and indicators. Current issues in tourism, 6(5), 369-414.

Ettlinger, N. (2001). Cultural Economic geography and a relational and microspace approach to trust, rationalities, networks, and change in collaborative workplaces. Journal of Economic Geography, 3, 145-171.

Faulconbridge, J. R. (2006). Stretching tacit knowledge beyond a local fix? Global spaces of learning in advertising professional service firms. Journal of Economic Geography, 6(4), 517540.

Frenken, K., Van Oort, F., \& Verburg, T. (2007). Related variety, unrelated variety and regional economic growth. Regional studies, 41(5), 685697.

Gertler, M. S. (1995). "Being there": proximity, organization, and culture in the development and adoption of advanced manufacturing technologies. Economic geography, 71(1), 1-26.

Grabher, G. (1993). Rediscovering the social in the economics of interfirm relations. The embedded firm: On the socioeconomics of industrial networks, 1-31.

Grabher, G. (2002). Cool projects, boring institutions: temporary collaboration in social context. Regional studies, 36(3), 205-214.

Granovetter, M. (1985). Economic action and social structure: The problem of embeddedness. American journal of sociology, 91(3), 481-510.

Henderson, J., Dicken, P., Hess, M., Coe, N., \& Yeung, H. W. C. (2002). Global production networks and the analysis of economic development. Review of international political economy, 9(3), 436-464.

Hjalager, A. M. (2000). Tourism destinations and the concept of industrial districts. Tourism and Hospitality Research, 2(3), 199-213.

Hoffmann, V.E., \& de Souza Campos, L. M. (2013). Instituições de suporte, serviços e desempenho: um estudo em aglomeração turística de Santa Catarina. RAC-Revista de Administração Contemporânea, 17(1).

Isard, W. (1956). Location and space-economy.

Isard, W. (1966). Methods of regional analysis (Vol. 4). Рипол Классик.

Jones, C., Hesterly, W. S., \& Borgatti, S. P. (1997). A general theory of network governance: Exchange conditions and social mechanisms. Academy of management review, 22(4), 911-945.

Judd, D. R. (1995). Promoting tourism in US cities. Tourism Management, 16(3), 175-187.

Laws, E. (1995). Tourist destination management: issues, analysis and policies. Routledge. 
Lazzeretti, L., \& Capone, F. (2008). Mapping and analysing local tourism systems in Italy, 19912001. Tourism Geographies, 10(2), 214-232.

Lee, R. (2002). 'Nice maps, shame about the theory'? Thinking geographically about the economic. Progress in Human Geography, 26(3), 333-355.

Malmberg, A., \& Maskell, P. (2002). The elusive concept of localization economies: towards a knowledge-based theory of spatial clustering. Environment and planning $A, 34(3)$, 429-449.

Maskell, P., \& Malmberg, A. (1999). The Competitiveness of Firms and Regions: 'Ubiquitification'and the Importance of Localized Learning. European Urban and Regional Studies, 6(1), 9-25.

Massey, D. (1985). New directions in space. In Social relations and spatial structures (pp. 9-19). Palgrave, London.

Massey, D. (2004). Geographies of responsibility. Geografiska Annaler: Series B, Human Geography, 86(1), 5-18.

Maulet, G. (2006). A framework to identify a localised tourism system. Tourism local systems and networking, 25-41.

Nelson, R. R., \& Winter, S. G. (1982). An Evolutionary Theory of Economic Change (Cambridge, MA: Belknap/Harvard University Press).

Nelson, R. R. (2009). An evolutionary theory of economic change. Harvard University Press.

O'Callaghan, C. (2012). Contrapuntal urbanisms: towards a postcolonial relational geography. Environment and Planning A, 44(8), 1930-1950.

Overman, H. G. (2004). Can we learn anything from economic geography proper? Journal of Economic Geography, 4(5), 501-516.

Polanyi, K. (1957). The economy as instituted pro- cess. Trade and market in the early empires, Glenco: Free Press, 243-70.

Porter, M. E. (1990). The competitive advantage of nations. Harvard business review, 68(2), 73-93. Porter, M E. (1998). On competition. Boston, MA: Harvard Business Review Press.

Porter, M. E. (1999). Competição: estratégias competitivas essenciais. Gulf Professional Publishing.

Pearce, D. G. (2014). Toward an integrative conceptual framework of destinations. Journal of Travel Research, 53(2), 141-153.

Pyke, F., Becattini, G., \& Sengenberger, W. (Eds.). (1990). Industrial districts and inter-firm co-operation in Italy. International Institute for Labour Studies, 125-154.

Pyke, F. \& Sengenberger, W. (1993). Los distritos industriales y las pequenas empresas: distritos industriales y regeneracion economica local. v. III. Ministério de Trabajo y Seguridad Social.

Randelli, F., Romei, P., \& Tortora, M. (2014). An evolutionary approach to the study of rural tourism: The case of Tuscany. Land Use Policy, 38, 276-281.

Ringer, G. (1998). Introduction. In Destinations: Cultural Landscapes of Tourism, edited by $\mathrm{G}$. Ringer. London: Routledge, 1-13.

Ritchie, J. B., \& Crouch, G. I. (2003). The competitive destination: A sustainable tourism perspective. Cabi.

Rutten, R. (2004). Inter-firm knowledge creation: A re-appreciation of embeddedness from a relational perspective. European Planning Studies, 12(5), 659-673.

Saarinen, J. (2004). 'Destinations in change' The transformation process of tourist destinations. Tourist studies, 4(2), 161-179. 
Shaw, G., \& Williams, A. M. (2004). Tourism and tourism spaces. Sage.

Sanz-Ibáñez, C., \& Anton Clavé, S. (2014). The evolution of destinations: Towards an evolutionary and relational economic geography approach. Tourism Geographies, 16(4), 563-579.

Saraniemi, S., \& Kylänen, M. (2011). Problematizing the concept of tourism destination: An analysis of different theoretical approaches. Journal of Travel Research, 50(2), 133-143.

Sayer, A. (1992). Method in social science: London. Routledge.

Sayer, A. (2000). Realism and social science. Sage.

Schmitz, H. (1997). Eficiência coletiva: caminho de crescimento para a indústria de pequeno porte. Ensaios FEE, 18(2), 164-200.

Scott, A. J. (1988). New industrial spaces: Flexible production organization and regional development in North America and Western Europe (Vol. 3). Pion Ltd.

Seaton, A. V., \& Bennett, M. M. (1996). The marketing of tourism products: Concepts, issues and cases. Cengage Learning EMEA.

Silva, P. M. (2015). Aglomerados e turismo: análise da produção científica nacional e internacional sobre o tema. Turismo-Visão e Ação, 16(2), 338-357.

Silva, J. A. (2006). A dimensão territorial no planejamento do desenvolvimento turístico no Brasil: modelo do pólo de crescimento versus modelo territorialista e endógeno. Revista Turismo em Análise, 17(3), 5-23.

Storper, M. (1997). The regional world: territorial development in a global economy. Guilford Press.

Storper, M., \& Walker, R. (1989). The capitalist imperative: Territory, technology, and industrial growth. Blackwell.
Sunley, P. (2008). Relational economic geography: a partial understanding or a new paradigm? Economic Geography, 84(1), 1-26.

Thrift, N. (2000a). Pandora's box? Cultural geographies of economies. In Clark, G.L., Feldman, M.P. and Gertler, M.S., editors, The Oxford handbook of economic geography, Oxford: Oxford University Press, 689-704.

Thrift, N. (2000b). Performing cultures in the new economy. Annals of the Association of American Geographers, 90(4), 674-692.

Vale, G. M.V., Amâncio, R., \& Braga de Lima, J. (2006). Criação e gestão de redes: uma estratégia competitiva para empresas e regiões. Revista de Administração-RAUSP, 41(2).

Walker, R., \& Storper, M. (1981). Capital and industrial location. Progress in Geography, 5(4), 473-509.

Williams, A. M. (2013). Mobilities and sustainable tourism: path-creating or path-dependent relationships? Journal of Sustainable Tourism, 21(4), 511-531.

Yeung, H. W. C. (1998). Capital, state and space: contesting the borderless world. Transactions of the Institute of British Geographers, 23(3), 291309.

Yeung, H. W. C. (2005). Rethinking relational economic geography. Transactions of the Institute of British Geographers, 30(1), 37-51.

\section{Informações dos autores}

\section{Adriana Fumi Chim-Miki}

Doutora em Turismo, Economia e Gestão pela Universidad de Las Palmas de Gran Canaria, Espanha. Mestrado em Geografia pela FURG. Graduada em Administração pela Universidade Federal do Rio Grande. Professora Adjunta na Unidade Acadêmica de Administração e contabilidade da Universidade Federal de Cam- 
pina Grande-UFCG, Paraíba. Coordenadora do Programa de Pós-Graduação em Administração da Universidade Federal de Campina Grande. Coordenadora do Grupo de Pesquisa REDES $6 C O$ - Competitividade, Cooperação, Coopetição, Co-Empreendedorismo, Cowork e Co-criação de Valor em redes Interoganizacionais e Gestão Social.

E-mail: adriana.chimmiki@gmail.com

ORCID - https://orcid.org/0000-0001-7685-2718

\section{Thays Cristina Domareski-Ruiz}

Doutora em Geografia pela Universidade Federal do Paraná, Brasil. Mestrado em Turismo e Hotelaria pela Universidade do Vale do Itajaí, Santa Catarina, Brasil. Bacharel em Turismo pela Universidade Estadual do Oeste do Paraná. Professora Adjunta do Departamento de Turismo da Universidade Federal do Paraná. Pesquisadora-colaboradora no Grupo de pesquisas REDES 6CO.

E-mail: thaysdomareski@gmail.com

ORCID - https://orcid.org/0000-0002-0183-2752 